\title{
Septal myectomy in context: Clinical acumen and procedural expertise
}

\author{
Steve R. Ommen, MD, ${ }^{a}$ and Joseph A. Dearani, $\mathrm{MD}^{\mathrm{b}}$
}

\footnotetext{
From the ${ }^{\mathrm{a} D i v i s i o n}$ of Cardiovascular Diseases, Mayo Clinic, Rochester, Minn; and the ${ }^{\mathrm{b}}$ Division of Cardiac Surgery, Mayo Clinic, Rochester, Minn.

Disclosures: Authors have nothing to disclose with regard to commercial support.

Received for publication Aug 16, 2015; accepted for publication Aug 18, 2015.

Address for reprints: Steve R. Ommen, MD, Division of Cardiovascular Diseases, Mayo Clinic, 200 1st Ave SW, Rochester, MN 55902 (E-mail: ommen.steve@mayo.edu).

J Thorac Cardiovasc Surg 2015;150:936-7

$0022-5223 / \$ 36.00$

Copyright (C) 2015 by The American Association for Thoracic Surgery

http://dx.doi.org/10.1016/j.jtcvs.2015.08.056
}

Surgical septal myectomy for the relief of symptomatic outflow tract obstruction in hypertrophic cardiomyopathy (HCM) has been of continual interest since its initial introduction nearly 60 years ago. Despite early concerns about overall safety, repeated investigations have shown myectomy to be safe, efficacious, and durable when performed by experienced surgeons in experienced centers. ${ }^{1,2}$ There are also data that suggest that myectomy may "normalize" survival. ${ }^{3}$ This compelling experience has positioned myectomy to be the preferred treatment for most patients with drug-refractory symptoms attributed to dynamic left ventricular outflow tract obstruction. ${ }^{4}$

In this issue of the Journal, Desai and colleagues ${ }^{5}$ provide an update on the Cleveland Clinic experience with myectomy in 990 patients and compared these patients with 540 other patients HCM who were seen at their center and not offered myectomy. They report better long-term survival in the patients who underwent myectomy than among the patients who did not undergo operation.

\section{IN CONTEXT}

Essentially, this study confirms those published in the past decade: myectomy is safe, with a procedural mortality rate approaching $0 \%$; myectomy is effective in relieving outflow tract obstruction and the attendant symptoms; and myectomy results in excellent postoperative survival. The survival curves reported in this issue by Desai and colleagues ${ }^{5}$ are nearly identical to those reported by Mayo Clinic and Toronto General Hospital. ${ }^{3,6}$ Data consistency and outcome from these institutions is notable. These most recent data focus on late survival or appropriate ICD discharge. In addition to overall survival, the prior study demonstrated improvements for myectomy patients in terms of HCM-related death and survival free from sudden cardiac death, and survival after myectomy was equivalent to that of an age- and sex-matched population. ${ }^{3}$ Indeed, the safety and efficacy of myectomy at institutions with large experiences has asymptotically approached the extremes

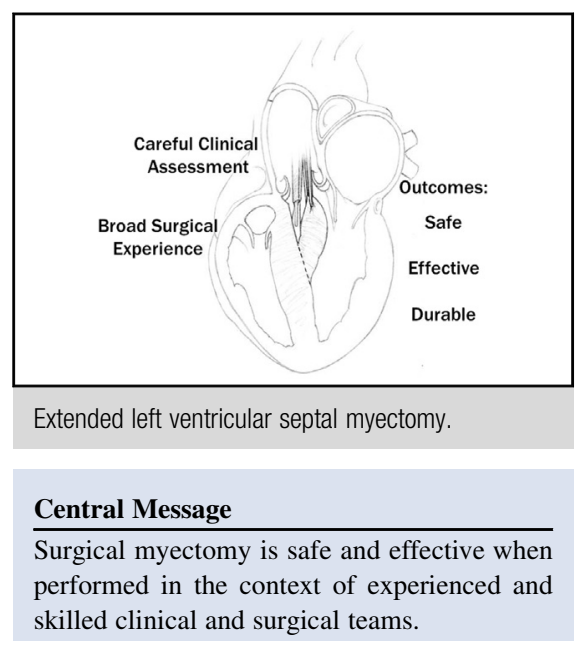

See Article page 928 to the point that it is practically untenable for subsequent studies to show any improvement in these end points.

\section{CLINICAL SKILLS}

Although HCM surgical centers have long included objective measures of exercise capacity in their assessment and decision making, Desai and colleagues ${ }^{5}$ highlight the finding that a significant number of their patients underwent myectomy on the basis of underperformance on treadmill testing. It is important that this is not interpreted as a mandate that myectomy (or other procedures) be offered on the basis of advanced New York Heart Association functional class or impaired exercise capacity. Clinicians understand that the decision to pursue a therapeutic path is not predicated on a single variable outside the broader clinical context of the patient and the impact on the patient's life. When examined closely, those clinicians who are skilled at helping patients to determine the best therapies often arrive at a tentative assessment on the basis of history and physical examination and then factor in other testing data. When the clinical impression and testing data are congruent, decision making is straightforward; when they are discordant, treatment recommendations are more difficult. There are numerous reasons other than outflow tract obstruction that contribute to exertional symptoms or underperformance on exercise testing. If the subjective New York Heart Association functional class and objective performance are conflicting, then thoughtful assessment, integration of the available data, and shared decision 
making with the patient will lead to optimal patient selection and outcomes with respect to the role of myectomy.

\section{SURGICAL EXPERIENCE}

Desai and colleagues ${ }^{5}$ also highlight another unique aspect of the HCM practice at their institution, the high frequency of mitral valve repair and replacement as an adjunct to surgical myectomy. Of the 990 patients, $25 \%$ had a mitral valve procedure performed during the initial operation or at subsequent operation for residual obstruction, and $4 \%$ of the total myectomy population received a mitral prosthesis. ${ }^{5}$ That is notable in light of the Mayo Clinic experience, in which mitral valve procedures of any kind have been considered necessary in fewer than $4 \%$ of patients undergoing myectomy. ${ }^{7,8}$ Although referral differences may explain some discrepancy, this seems unlikely given the robust experiences at both of these institutions. Rather, it is more likely that the Cleveland team has evolved toward mitral valve manipulation as part of their surgical approach. In parallel, our team has developed a comfort with a more extensive myectomy when needed, with sparing of the mitral valve when the mechanism of regurgitation is systolic anterior motion. We have not seen higher rates of subsequent mitral regurgitation or the need for mitral intervention, nor have we seen untoward consequences from a more extensive myectomy. ${ }^{9}$ In the absence of structural mitral valve disease (flail, prolapse, or accessory papillary muscle or chordae), our approach is to perform isolated extended myectomy only. After myectomy, postbypass intraoperative transesophageal echocardiography and direct pressure measurements are analyzed for residual obstruction or mitral regurgitation. Residual obstruction is addressed by further extending (to a more apical extent) the myectomy, particularly when there is residual septal and free wall hypertrophy. With this approach, mitral valve repair or papillary muscle repositioning is rarely needed. In short, our philosophy has been to address the muscular hypertrophy and to spare the valve.
Taken together with existing evidence, the report by Desai and colleagues ${ }^{5}$ confirms the safety and efficacy of surgical myectomy. The excellent results observed in this report and others during the past decade are based on experiences of expert centers and surgeons, as recommended by the American College of Cardiology, American Heart Association, and European Society of Cardiology., ${ }^{40}$

\section{References}

1. Ommen SR, Shah PM, Tajik AJ. Left ventricular outflow tract obstruction in hypertrophic cardiomyopathy: past, present and future. Heart. 2008;94:1276-81.

2. Maron BJ, Dearani JA, Ommen SR, Maron MS, Schaff HV, Gersh BJ, et al. The case for surgery in obstructive hypertrophic cardiomyopathy. J Am Coll Cardiol. 2004; 44:2044-53.

3. Ommen SR, Maron BJ, Olivotto I, Maron MS, Cecchi F, Betocchi S, et al. Long term effects of surgical septal myectomy on survival in patients with obstructive hypertrophic cardiomyopathy. J Am Coll Cardiol. 2005;46:470-6.

4. Gersh BJ, Maron BJ, Bonow RO, Dearani JA, Fifer MA, Link MS, et al. American College of Cardiology Foundation/American Heart Association Task Force on Practice Guidelines; American Association for Thoracic Surgery; American Society of Echocardiography; American Society of Nuclear Cardiology; Heart Failure Society of America; Heart Rhythm Society; Society for Cardiovascular Angiography and Interventions; Society of Thoracic Surgeons. 2011 ACCF/ AHA guideline for the diagnosis and treatment of hypertrophic cardiomyopathy a report of the American College of Cardiology Foundation/American Heart Association Task Force on Practice Guidelines. Circulation. 2011;124:e783-831.

5. Desai MY, Smedira NG, Bhonsale A, Thamilarasan M, Lytle BW, Lever HM. Symptom assessment and exercise impairment in surgical decision making in hypertrophic obstructive cardiomyopathy: relationship to outcomes. J Thorac Cardiovasc Surg. 2015;150:928-35.

6. Woo A, Williams WG, Choi R, Wigle ED, Rozenblyum E, Fedwick K, et al. Clinical and echocardiographic determinants of long-term survival after surgical myectomy in obstructive hypertrophic cardiomyopathy. Circulation. 2005;111: 2033-41.

7. Minikata K, Dearani JA, Nishimura RA, Maron BJ, Danielson GK. Extended septal myectomy for hypertrophic cardiomyopathy with anomalous mitral papillary muscles or chordae. J Thorac Cardiovasc Surg. 2004;127:481-9.

8. Wan CK, Dearani JA, Sundt TM III, Ommen SR, Schaff HV. What is the best surgical treatment for obstructive hypertrophic cardiomyopathy and degenerative mitral regurgitation? Ann Thorac Surg. 2009;88:727-31; discussion 731-2.

9. Dearani JA, Ommen SR, Gersh BJ, Schaff HV, Danielson GK. Surgery insight: septal myectomy for obstructive hypertrophic cardiomyopathy-the Mayo Clinic experience. Nat Clin Pract Cardiovasc Med. 2007;4:503-12.

10. Authors/Task Force members, Elliott PM, Anastakis A, Borger MA, Borggrefe M, Cecchi F, Charron P, et al. 2014 ESC guidelines on diagnosis and management of hypertrophic cardiomyopathy: the Task Force for the Diagnosis and Management of Hypertrophic Cardiomyopathy of the European Society of Cardiology (ESC). Eur Heart J. 2014;35:2733-79. 